\title{
BMJ Global Health An analysis of clinical predictive values for radiographic pneumonia in children
}

To cite: Rees CA, Basnet S, Gentile A, et al. An analysis of clinical predictive values for radiographic pneumonia in children. BMJ Global Health 2020;5:e002708. doi:10.1136/ bmjgh-2020-002708

Handling editor Alberto L Garcia-Basteiro

- Additional material is published online only. To view please visit the journal online (http://dx.doi.org/10.1136/ bmjgh-2020-002708).

Received 22 April 2020 Revised 9 June 2020 Accepted 24 June 2020

\section{Check for updates}

(c) Author(s) (or their employer(s)) 2020. Re-use permitted under CC BY-NC. No commercial re-use. See rights and permissions. Published by BMJ.

For numbered affiliations see end of article.

\section{Correspondence to} Dr Mark I Neuman; mark.neuman@childrens. harvard.edu

\section{ABSTRACT}

Introduction Healthcare providers in resource-limited settings rely on the presence of tachypnoea and chest indrawing to establish a diagnosis of pneumonia in children. We aimed to determine the test characteristics of commonly assessed signs and symptoms for the radiographic diagnosis of pneumonia in children 0-59 months of age.

Methods We conducted an analysis using patientlevel pooled data from 41 shared datasets of paediatric pneumonia. We included hospital-based studies in which $>80 \%$ of children had chest radiography performed. Primary endpoint pneumonia (presence of dense opacity occupying a portion or entire lobe of the lung or presence of pleural effusion on chest radiograph) was used as the reference criterion radiographic standard. We assessed the sensitivity, specificity, and likelihood ratios for clinical findings, and combinations of findings, for the diagnosis of primary endpoint pneumonia among children 0-59 months of age.

Results Ten studies met inclusion criteria comprising 15029 children; $24.9 \%(n=3743)$ had radiographic pneumonia. The presence of age-based tachypnoea demonstrated a sensitivity of 0.92 and a specificity of 0.22 while lower chest indrawing revealed a sensitivity of 0.74 and specificity of 0.15 for the diagnosis of radiographic pneumonia. The sensitivity and specificity for oxygen saturation $<90 \%$ was 0.40 and 0.67 , respectively, and was 0.17 and 0.88 for oxygen saturation $<85 \%$. Specificity was improved when individual clinical factors such as tachypnoea, fever and hypoxaemia were combined, however, the sensitivity was lower.

Conclusions No single sign or symptom was strongly associated with radiographic primary end point pneumonia in children. Performance characteristics were improved by combining individual signs and symptoms.

\section{INTRODUCTION}

Pneumonia is the leading cause of morbidity and mortality among children 1-59 months of age worldwide. ${ }^{12}$ Annually, there are over 800 000 deaths from pneumonia among children worldwide. ${ }^{2}$ Such morbidity and mortality

\section{Key questions}

What is already known?

- Pneumonia is the leading cause of morbidity and mortality among children 1-59 months of age worldwide.

- The diagnosis of childhood pneumonia is often established based on clinical findings, as the definitive aetiological diagnosis can only be made using invasive testing.

- Antibiotic treatment decisions for children with suspected pneumonia in low-income and middleincome countries rely largely on clinical findings, including tachypnoea and chest indrawing.

What are the new findings?

- Our study of over 15000 children from geographically diverse parts of the world is the largest to date to assess the test characteristics of clinical signs and symptoms for radiographic pneumonia among children 0-59 months of age.

- Individual findings commonly used to identify pneumonia in resource-limited settings, including tachypnoea and lower chest indrawing, had low specificity for the diagnosis of radiographic pneumonia.

- The combination of tachypnoea and fever, tachypnoea and hypoxaemia, and fever and hypoxaemia led to improved specificity with only a modest decrement in sensitivity for radiographic pneumonia.

\section{What do the new findings imply?}

- Individual symptoms and physical examination findings are not highly predictive of primary endpoint pneumonia on chest radiograph.

- Combining temperature, respiratory rate, and oxygen saturation improves specificity in the identification of radiographic pneumonia.

- The diagnostic performance of a combination of signs and symptoms should be explored in a prospective fashion to allow for a judicious approach to antibiotic treatment in children with suspected pneumonia.

from childhood pneumonia disproportionately affects children in low-income and middle-income countries, with nearly $90 \%$ 
of pneumonia-related deaths occurring in sub-Saharan Africa and South and Southeastern Asia alone. ${ }^{23}$ Despite the large global burden of disease of childhood pneumonia, a commonly agreed upon standardised approach to the diagnosis of pneumonia is lacking. ${ }^{4}$

The diagnosis of childhood pneumonia is often established based on clinical findings, as the definitive diagnosis can only be made using invasive testing such as lung biopsies, which are reserved for patients in whom traditional therapeutics have failed. ${ }^{5}$ As such, chest radiography is often used in clinical practice for the diagnosis of childhood pneumonia and has been used as a reference standard in previous investigations. ${ }^{6-10}$ In a large, multicountry study in Asia and sub-Saharan Africa, chest radiography correlated with clinically diagnosed pneumonia in over half of patients included. ${ }^{11}$ Nevertheless, the routine use of chest radiography for the diagnosis of childhood pneumonia in the outpatient setting is not recommended by the Infectious Disease Society of America. ${ }^{5}$ Similarly, the World Health Organization's (WHO) integrated management of childhood illness (IMCI) chart booklet used in many low-income and middle-income countries, recommends the diagnosis of pneumonia be made clinically, with reliance on tachypnoea or lower chest indrawing in a child with cough or difficulty breathing. ${ }^{12}{ }^{13}$ However, recent analyses suggest that the sensitivity $(54 \%-62 \%)$ and specificity $(59 \%-$ $64 \%)$ of tachypnoea and sensitivity $(38 \%-48 \%)$ and specificity $(72 \%-80 \%)$ of lower chest indrawing is lower than originally estimated. ${ }^{91014}$ Concerns around the low specificity of the WHO pneumonia signs, and potential excess antibiotic prescribing, prompted further evaluation of these clinical criteria for the diagnosis of pneumonia in children.

The development of sensitive and specific diagnostic clinical criteria for childhood pneumonia is imperative as chest radiography is not routinely available in many low- and middle-income countries. Previous systematic reviews evaluating the utility of symptoms and physical examination findings for the diagnosis of childhood pneumonia have relied on data reported in published articles, without access to individual patient-level data. ${ }^{9} 10$ Additionally, the overwhelming majority of these investigations were conducted in high-income countries. The reliance on predetermined cut-points from published articles for clinical criteria such as respiratory rate (RR) and oxygen saturation $\left(\mathrm{SpO}_{2}\right)$ may lead to imprecision in the analysis of diagnostic clinical criteria for childhood pneumonia.

With the aim of better understanding the clinical diagnostic criteria for childhood pneumonia, the WHO established the Pneumonia REsearch Partnership to Assess WHO Recommendations (PREPARE) study group. The PREPARE study group obtained patient-level data from 30 study groups, comprising 41 separate datasets on childhood pneumonia from across the world. Using the large, representative PREPARE dataset, our objective was to determine the sensitivity and specificity of key clinical features and combination of clinical features in the diagnosis of childhood pneumonia against a radiological reference standard. Accurate identification of children with pneumonia using clinical factors could potentially allow providers to more accurately diagnose childhood pneumonia and, subsequently, more appropriately target antibiotic therapy.

\section{METHODS \\ Study design}

We conducted an analysis using datasets from the WHO's PREPARE study group. The WHO PREPARE study group assembled datasets through retrospective identification of primary data on childhood pneumonia from over 20 low- and middle-income countries in Asia, Africa and Latin America as well as two high-income countries (ie, the USA and Australia). Study sites were considered for inclusion in WHO PREPARE study group if they included data from control arms of vaccine trials, communitybased cohorts, and hospital-based studies with clinical and epidemiological data collected. Potential study sites were identified from a list of contributors to a systematic review of global burden of hospital admissions for severe acute lower respiratory infections in children. ${ }^{15}$ Based on a review of the paediatric pneumonia literature, we identified 50 groups who were involved in pneumonia research who had published articles between 2005 and 2018. These groups had conducted pneumonia research with and without interventions, randomised controlled trials, epidemiological studies, and vaccine trials. We invited all 50 study groups to participate by attending an inception meeting in Ferny-Voltaire, France. Representatives from 38 groups attended that meeting where each investigator presented their site data. As a result of that meeting, 30 study groups agreed to participate and provided 41 unique databases for the WHO PREPARE study group. Datasets were limited to include only data on children 0-59 months of age, despite potentially containing data from older children.

For this study, to include datasets in which chest radiography was performed in a generalisable fashion, we limited our analysis to datasets of hospital-based studies that included data on chest radiography and had a chest radiography performed in $\geq 80 \%$ of cases. Studies in which chest radiography was performed in $<80 \%$ of cases may have suffered from selection bias as chest radiography may have been performed only in children with severe illness and at higher risk of pneumonia and were excluded. Community-based studies were not included as chest radiography was rarely performed.

\section{Patient and public involvement statement}

The development of the research question was informed by the large disease burden of pneumonia among children worldwide. Patients were not involved in the design, recruitment, or conduct of the study. Results of this study will be made publicly available through publication 
where study participants may access them. Patients were not advisers in this study.

\section{Pneumonia case definition}

Datasets were included in this analysis if they included data on children presenting acutely with cough or difficulty breathing and included pneumonia as defined by the WHO radiological criteria for primary endpoint pneumonia $^{6}(\mathrm{n}=8)$ or if they used lobar consolidation on chest radiography as diagnostic criteria for pneumonia $(n=2)$. Though originally created for use in vaccine trials, primary endpoint pneumonia has been applied to large cohorts of children with pneumonia in several low- and middle-income countries with good inter-rater reliability. ${ }^{16}$ A majority of the datasets $(n=6)$ included in this analysis enrolled children with tachypnoea, as this is the primary determinant of pneumonia based on the WHO IMCI chart booklet. Primary endpoint pneumonia was selected as the radiographic reference standard as it is clearly defined, is reliable across studies, is independent of predictor clinical variables that are often studied in work evaluating childhood pneumonia, is a clear indication of pneumonia and not viral acute lower respiratory tract infection, and highlights bacterial pneumonia that requires antibiotic treatment. Lobar consolidation was used as a reference standard in two included datasets and has shown high inter-rater reliability among paediatric radiologists in prospective studies. ${ }^{17}$ All radiographs in the included studies were interpreted by a radiologist; many of the studies required review by two or more radiologists.

\section{Data analysis}

Using radiographic pneumonia as the reference standard, we evaluated the sensitivity, specificity, and likelihood ratios (LRs) for individual clinical findings. We calculated 95\% CIs for all +LR and -LRs. Candidate variables from patients' histories that were used to calculate test characteristics included history of cough, fever, difficulty breathing, vomiting, and poor feeding. We evaluated the test characteristics of tachypnoea as defined by the WHO IMCI age-specific cutoffs (ie, RR of $\geq 60$ breaths per minutes in children $<2$ months old, $>50$ breaths per minute in children $2-11$ months old, and $\geq 40$ breaths per minute in children $12-59$ months old $)^{18}$ as well as the addition of five and 10 respirations per minute to the age-specific WHO classification of tachypnoea.

Using radiographic pneumonia as the reference standard, we also evaluated the test characteristics of lower chest indrawing, nasal flaring, grunting, wheezing, body temperature, $\mathrm{SpO}_{2}$, presence of rales or crepitations, inability to drink, presence of convulsions, cyanosis, head nodding/bobbing, presence of irritability, lethargy and presence of any danger sign (ie, inability to drink, convulsions, cyanosis, head nodding/bobbing, irritability, abnormally sleepy, lethargy, nasal flaring, grunting, and $\left.\mathrm{SpO}_{2}<90 \%\right)$. We stratified analyses by age ( $<2$ months, 2-11 months, and 12-59 months) and by the presence or absence of wheezing. We assessed the test characteristics of varying age-specific $\mathrm{RR}$ and $\mathrm{SpO}_{2}$ in patients both with and without wheezing to eliminate children who may have asthma who are sometimes included in studies evaluating pneumonia. We also assessed the sensitivity, specificity, and LRs of combinations of clinical signs and symptoms compared with the reference standard of radiographic pneumonia. We had a study power of $>95 \%$ to detect a difference in radiographic pneumonia of at least $7 \%$ between children who had some clinical features of pneumonia (eg, presence of chest indrawing, any danger sign, temperature $\geq 38^{\circ} \mathrm{C}$, or $\mathrm{SpO}_{2}<90 \%$ ) and those who did not have these clinical features. All analyses were conducted using Stata V.14 (StataCorp, College Station, TX, USA).

\section{RESULTS}

Of the 41 separate datasets, 26 were hospital based, of which 10 met inclusion criteria, containing a total of 15 029 patients (figure 1). The mean age of patients was



Figure 1 Hospital-based studies including children 0 to $\leq 59$ months of age. ${ }^{a}$ Chest radiography not performed or data regarding presence of pneumonia/infiltrate not recorded. ${ }^{\mathrm{b}}$ Radiographic pneumonia in 3743 patients (24.9\%). PREPARE, Pneumonia REsearch Partnership to Assess WHO Recommendations. 
Table 1 Study characteristics

\begin{tabular}{|c|c|c|c|c|c|c|}
\hline Study & Location & $\begin{array}{l}\text { Age } \\
\text { range }\end{array}$ & Inclusion and exclusion criteria & $\begin{array}{l}\text { Sample } \\
\text { size }\end{array}$ & $\begin{array}{l}\text { Radiographic } \\
\text { pneumonia, } \\
\text { N (\%) }\end{array}$ & $\begin{array}{l}\text { Definition of } \\
\text { pneumonia by } \\
\text { chest radiograph }\end{array}$ \\
\hline $\begin{array}{l}\text { Puumalainen et al } \\
\text { and Arcay, et al. } \\
\text { (ARIVAC) }^{48} 49\end{array}$ & Philippines & $\begin{array}{l}6 \text { weeks } \\
\text { to } 59 \\
\text { months }\end{array}$ & $\begin{array}{l}\text { Tachypnoea*, lower chest indrawing } \\
\text { (severe pneumonia) } \dagger \text { or cyanosis } \\
\text { and/or inability to drink (very severe } \\
\text { pneumonia) } \ddagger\end{array}$ & 1153 & $187(16.2)$ & $\begin{array}{l}\text { Primary end } \\
\text { point pneumonia } \\
(\text { PEP)§ }\end{array}$ \\
\hline Basnet et $\left.a\right|^{50}$ & Nepal & $\begin{array}{l}2-35 \\
\text { months }\end{array}$ & $\begin{array}{l}\text { Cough }<14 \text { days and/or difficulty } \\
\text { breathing } \leq 72 \text { hours with presence of } \\
\text { lower chest indrawing, provided lower } \\
\text { chest indrawing persisted after } 3 \text { doses } \\
\text { of bronchodilators. }\end{array}$ & 551 & $135(24.5)$ & $\begin{array}{l}\text { Lobar } \\
\text { pneumonia/ } \\
\text { consolidationף }\end{array}$ \\
\hline Gentile et $a l^{51}$ & Argentina & $\begin{array}{l}0-59 \\
\text { months }\end{array}$ & Children hospitalised with pneumonia. & 401 & $201(50.1)$ & PEP§ \\
\hline Gessner et $a l^{52}$ & Indonesia & $\begin{array}{l}0-24 \\
\text { months }\end{array}$ & $\begin{array}{l}\text { WHO defined non-severe }{ }^{* *} \text { and severe } \\
\text { pneumonia†. }\end{array}$ & 5814 & $1025(17.6)$ & PEP§ \\
\hline Tan et $a l^{54}$ & Indonesia & $<5$ years & $\begin{array}{l}\text { All children with diagnosis of } \\
\text { pneumonia and having } \geq 1 \text { of the } \\
\text { following: fever, cough, dyspnoea, or } \\
\text { tachypnoea*. }\end{array}$ & 1251 & $128(10.2)$ & $\begin{array}{l}\text { Lobar } \\
\text { pneumonia/ } \\
\text { consolidationף }\end{array}$ \\
\hline Neuman, et $a l^{24}$ & USA & $\begin{array}{l}0-59 \\
\text { months }\end{array}$ & $\begin{array}{l}\text { Children with chest X-ray performed } \\
\text { for suspicion of pneumonia. Excluded } \\
\text { children with chronic conditions. }\end{array}$ & 1796 & $161(9.0)$ & PEP§ \\
\hline O'Grady et $a l^{55}$ & $\begin{array}{l}\text { Central } \\
\text { Australia }\end{array}$ & $\begin{array}{l}0-59 \\
\text { months }\end{array}$ & $\begin{array}{l}\text { Child with cough with tachypnoea* } \\
\text { and/or chest indrawing } \dagger \text {. Excluded } \\
\text { children with wheezing and chronic } \\
\text { conditions. }\end{array}$ & 147 & $40(27.2)$ & PEP§ \\
\hline
\end{tabular}

*Tachypnoea: respiratory rate $\geq 60$ per minute in infants $<2$ months old, $\geq 50$ per minute in infants $2-11$ months old, or $\geq 40$ per minute in children 12-59 months of age.

†Severe pneumonia (old WHO pneumonia classification): cough and/or fast breathing with lower chest indrawing.

¥Very severe pneumonia (old WHO pneumonia classification): one or more danger sign including abnormally sleepy, lethargy, central cyanosis, inability to drink, convulsions, head nodding/bobbing, nasal flaring or grunting.

§PEP: a dense opacity that may be a fluffy consolidation of a portion or whole of a lobe or of the entire lung, often containing air bronchograms and sometimes associated with pleural effusion.

ILobar pneumonia or consolidation: Chest X-ray findings showing lobar pneumonia or consolidation.

${ }^{\star *}$ Non-severe pneumonia: cough and fast breathing, defined as respiratory rate of $\geq 50$ per minute in children $2-11$ months old or $\geq 40$ per minute in children 12-59 months old.

13.0 months (standard deviation \pm 12.3 ) with median of 9.0 months (4.4-16.9). Details regarding the setting and patient population for the 10 included datasets are shown in table 1. Of the 15029 patients included, $24.9 \%$ $(\mathrm{n}=3743)$ had radiographic pneumonia.

The sensitivity and specificity of individual symptoms and physical examination findings for the diagnosis of radiographic pneumonia are shown in table 2 . No single sign or symptom was strongly associated with radiographic pneumonia. The presence of poor feeding (+LR 1.67 (95\% CI 1.29 to 2.16)), axillary/body temperature $\geq 38^{\circ} \mathrm{C}$ (+LR 1.36 (95\% CI 1.31 to 1.41 )), head nodding/ bobbing (+LR 1.84 (95\%CI 1.38 to 2.45$)$ ), grunting (+LR
$1.72(95 \% \mathrm{CI} 1.27$ to 2.33$)$ ), and hypoxaemia at $\mathrm{SpO}_{2}$ $<85 \%$ (+LR 1.42 [95\% CI 1.27 to 1.59 )) were weakly associated with the presence of radiographic pneumonia, while the absence of the following features was associated with a lower likelihood of radiographic pneumonia: axillary/body temperature $\geq 38^{\circ} \mathrm{C}$ (-LR 0.77 (95\% CI 0.74 to 0.80$)$ ), rales/crepitations (-LR 0.73 (95\% CI 0.66 to $0.80)$ ), and $\mathrm{SpO}_{2}<95 \%$ (-LR 0.83 (95\% CI 0.78 to 0.88$)$ ).

Age-specific RR thresholds were neither highly sensitive nor specific for the radiographic diagnosis of pneumonia in the overall cohort and among the subset of children without wheezing (table 3). Among children 2-11 months of age, those with $R R \geq 60$ breaths per minute 


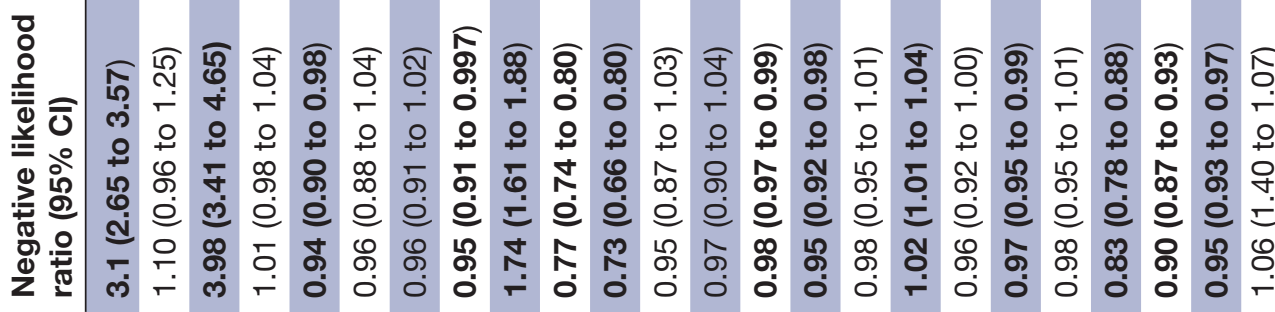

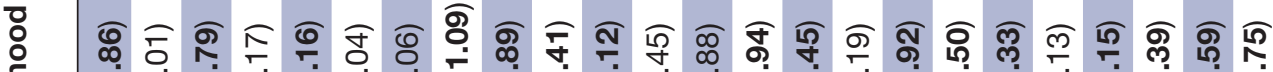

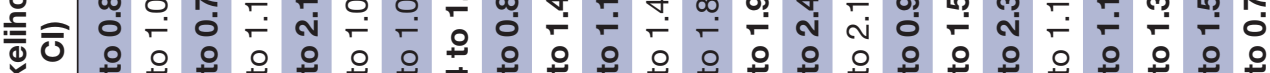

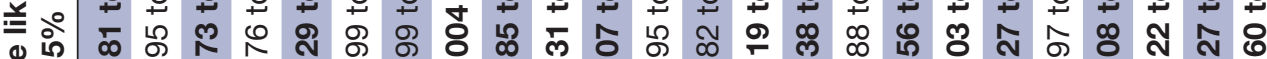


负

के 두

$\sum_{\frac{2}{2}}^{\frac{2}{2}}$

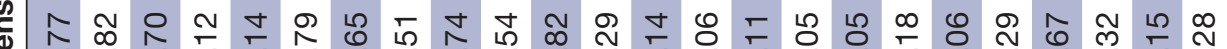

을

을

흘 के है है

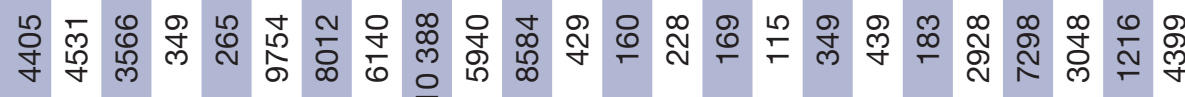

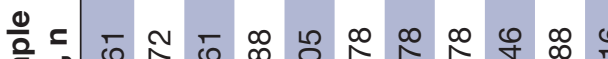

ஸे क 字 เั



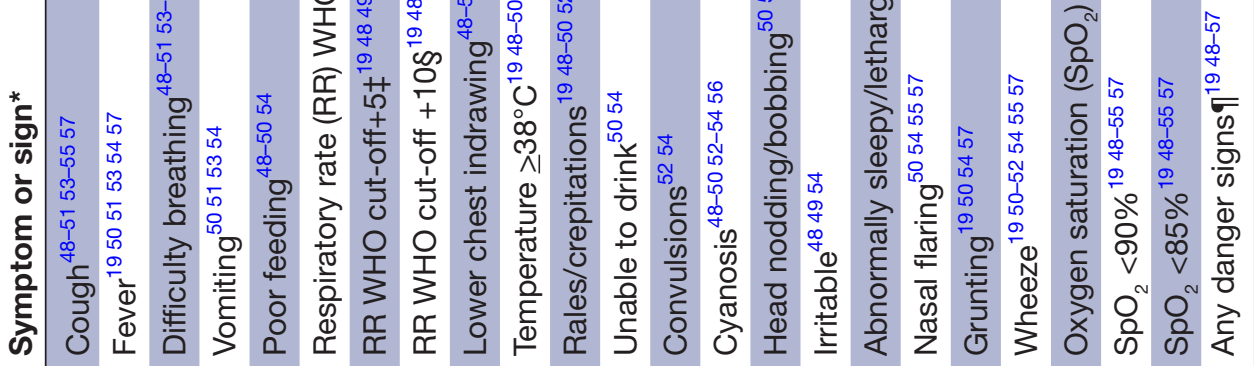
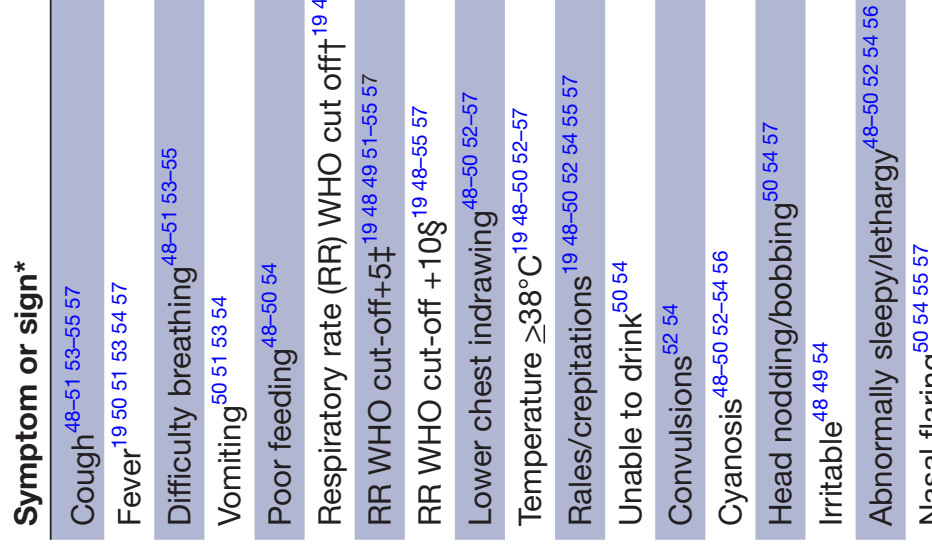

จำ 흥

ำ ণั ญ̊

$\stackrel{\sim}{\sim}$

힌유

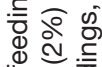

ㅎำ

으. $\frac{5}{10}$

흔은

จิ ते के

은 ㅇํㅇ

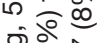

ฮั

हั ฐ

文 क

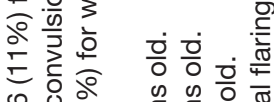

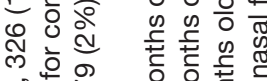

ㅇํㅇำ

응

离 向言

는 는

褰 응

흐응 응

วิ $\frac{0}{5}$ ช

造 흔 은

๙ $\frac{2}{2} \frac{\pi}{\frac{\pi}{4}}$

๘) ำ

ख ल ๗

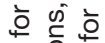

ㅇํㅇㅎㅠ 항

仓ै. 웡

$\infty$ 只

ᄃे के वें

훙 뜬

원

ऽ ले ఖ

응

ल

के की

응

每需

ธิ ญ 흐

롱

누을

윌 을

웜

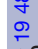

ำ

占

ช

을 응

든 닝ㅇㅇ

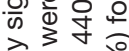

言 क वे

ह ह 을

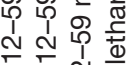

ฮ ญ จ

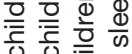

$\subseteq . \subseteq$ ป

Ф)

ह.

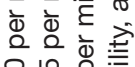

워 눙

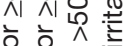

흥 흥 흥 하

की की की

등 응

ᄃ $匚$ E.

N $\stackrel{1}{\sim} \stackrel{1}{\sim}$

营 点

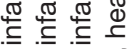

$\subseteq . \subseteq$.

ه

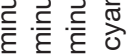

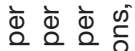



흥 흥 흥 둥

을 象

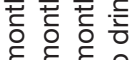

$\varepsilon \varepsilon \varepsilon$

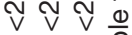

की



$\leq . \leq \dot{0}$

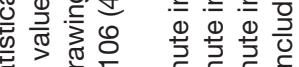

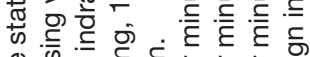

凹

Ф

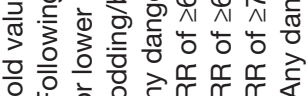

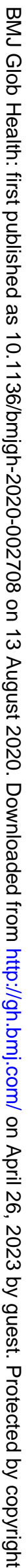


Table 3 Test characteristics of varying respiratory rates (RRs) by age group among all children and those without wheezing*

\begin{tabular}{|c|c|c|c|c|c|c|}
\hline $\mathbf{R R}$ & $\begin{array}{l}\text { Patients with } \\
\text { RR above } \\
\text { threshold, } n\end{array}$ & $\begin{array}{l}\text { Patients with } \\
\text { radiographic } \\
\text { pneumonia, n }\end{array}$ & Sensitivity & Specificity & $\begin{array}{l}\text { Positive likelihood } \\
\text { ratio }(95 \% \mathrm{Cl})\end{array}$ & $\begin{array}{l}\text { Negative } \\
\text { likelihood ratio } \\
(95 \% \mathrm{Cl})\end{array}$ \\
\hline \multicolumn{7}{|l|}{ All children } \\
\hline \multicolumn{7}{|c|}{ Age $<2$ months $(n=1073)$} \\
\hline $\mathrm{RR} \geq 60$ & 650 & 104 & 0.60 & 0.39 & 0.98 (0.86 to 1.12$)$ & $1.03(0.84$ to 1.25$)$ \\
\hline $\mathrm{RR} \geq 65$ & 357 & 63 & 0.36 & 0.67 & $1.11(0.89$ to 1.38$)$ & 0.95 (0.84 to 1.07$)$ \\
\hline$R R \geq 70$ & 182 & 30 & 0.17 & 0.83 & $1.02(0.71$ to 1.46$)$ & 1.00 (0.93 to 1.07$)$ \\
\hline \multicolumn{7}{|c|}{ Age $2-11$ months $(n=7145)$} \\
\hline$R R \geq 50$ & 5986 & 1187 & 0.85 & 0.17 & $1.02(1.00$ to 1.05$)$ & 0.89 (0.77 to 1.02$)$ \\
\hline $\mathrm{RR} \geq 55$ & 4926 & 982 & 0.71 & 0.31 & 1.03 (0.99 to 1.07$)$ & 0.94 (0.86 to 1.03$)$ \\
\hline$R R \geq 60$ & 3717 & 772 & 0.55 & 0.49 & $1.08(1.03$ to 1.14$)$ & 0.91 (0.86 to 0.97$)$ \\
\hline \multicolumn{7}{|c|}{ Age $12-59$ months $(n=4260)$} \\
\hline$R R \geq 40$ & 3140 & 715 & 0.74 & 0.26 & $1.00(0.96$ to 1.04$)$ & 1.00 (0.89 to 1.13$)$ \\
\hline$R R \geq 45$ & 2685 & 603 & 0.62 & 0.37 & $0.98(0.93$ to 1.04$)$ & 1.03 (0.94 to 1.13$)$ \\
\hline$R R \geq 50$ & 2268 & 499 & 0.51 & 0.46 & 0.96 (0.89 to 1.02$)$ & 1.05 (0.98 to 1.13$)$ \\
\hline \multicolumn{7}{|c|}{ Children without wheezing } \\
\hline \multicolumn{7}{|c|}{ Age $<2$ months $(n=937)$} \\
\hline $\mathrm{RR} \geq 60$ & 570 & 85 & 0.60 & 0.39 & $0.99(0.86$ to 1.14$)$ & $1.02(0.81$ to 1.27$)$ \\
\hline$R R \geq 65$ & 318 & 54 & 0.38 & 0.67 & $1.15(0.92$ to 1.46$)$ & $0.92(0.80$ to 1.06$)$ \\
\hline $\mathrm{RR} \geq 70$ & 162 & 26 & 0.18 & 0.83 & $1.08(0.74$ to 1.58$)$ & 0.98 (0.90 to 1.07$)$ \\
\hline \multicolumn{7}{|c|}{ Age $2-11$ months $(n=5340)$} \\
\hline $\mathrm{RR} \geq 50$ & 4449 & 886 & 0.84 & 0.17 & 1.01 (0.99 to 1.04$)$ & 0.93 (0.79 to 1.08$)$ \\
\hline$R R \geq 55$ & 3650 & 730 & 0.69 & 0.32 & $1.02(0.97$ to 1.07$)$ & 0.96 (0.86 to 1.06$)$ \\
\hline$R R \geq 60$ & 2731 & 571 & 0.54 & 0.50 & $1.08(1.01$ to 1.15$)$ & $0.92(0.86$ to 0.99$)$ \\
\hline \multicolumn{7}{|c|}{ Age $12-59$ months $(n=3225)$} \\
\hline $\mathrm{RR} \geq 40$ & 2270 & 540 & 0.70 & 0.29 & 0.98 (0.93 to 1.04$)$ & $1.04(0.92$ to 1.17$)$ \\
\hline $\mathrm{RR} \geq 45$ & 1937 & 449 & 0.58 & 0.39 & 0.95 (0.89 to 1.02$)$ & 1.07 (0.98 to 1.18$)$ \\
\hline$R R \geq 50$ & 1612 & 368 & 0.47 & 0.49 & $0.93(0.86$ to 1.02$)$ & 1.07 (0.99 to 1.16$)$ \\
\hline
\end{tabular}

Bold values are statistically significant.

*182 missing values for RR were excluded from the analysis.

were more likely to have radiographic pneumonia $(+\mathrm{LR}$ 1.08 (95\% CI 1.03 to 1.14$)$ ), while those with RR $<60$ were less likely to have radiographic pneumonia (-LR 0.91 (95\% CI 0.86 to 0.97$)$ ).

The test characteristics of $\mathrm{SpO}_{2}$ for radiographic pneumonia for all children and those without wheezing are shown in online supplementary table 1. Sensitivity decreased and specificity increased with increasing levels of hypoxaemia, although no single threshold had optimal test characteristics for the identification of radiographic pneumonia.

The combinations of varying degrees of hypoxaemia, fever and tachypnoea are shown in tables 4-6. At each $\mathrm{SpO}_{2}$ category, specificity increased with increasing RR. Among children with $\mathrm{SpO}_{2}<90 \%$, children with RRs $\geq 10$ breaths per minute above the WHO threshold for age-defined tachypnoea were slightly more likely to have radiographic pneumonia (+LR 1.40 (95\% CI 1.28 to 1.53$)$ ), while those without this degree of tachypnoea were less likely to have radiographic pneumonia (-LR $0.92(95 \%$ CI 0.90 to 0.94$)$ ) (table 4$)$. Among the subset of children with temperature $\geq 38^{\circ} \mathrm{C}$, those with an RR $\geq 10$ breaths per minute above the WHO threshold for age-defined tachypnoea were slightly more likely to have radiographic pneumonia (+LR 1.24 (95\%CI 1.14 to 1.35)) (table 5). The combination of temperature $\geq 38^{\circ} \mathrm{C}$ and $\mathrm{SpO}_{2}<85 \%$ was highly specific for radiographic pneumonia (specificity 0.96 , (95\% CI 0.96 to 0.97$)$ ) while the sensitivity was quite low (sensitivity 0.07 , (95\% CI 0.06 to 0.08$)$ ) (table 6).

\section{DISCUSSION}

Our study of over 15000 children from geographically diverse parts of the world is the largest to date assessing the test characteristics of clinical signs and symptoms for radiographic pneumonia among children 0-59 months of age. We observed that individual findings commonly 
Table 4 Test characteristics of varying respiratory rates (RRs) with $\mathrm{SpO}_{2}$ levels in children

\section{Patients}

with RR

above Radiographic

threshold, $\mathbf{n}$ pneumonia,

\begin{tabular}{|c|c|c|c|c|c|c|}
\hline $\mathrm{RR}$ and $\mathrm{SpO}_{2}$ & $(n=9360)$ & $n(n=2444)$ & Sensitivity & Specificity & ratio $(95 \% \mathrm{Cl})$ & ratio $(95 \% \mathrm{Cl})$ \\
\hline \multicolumn{7}{|l|}{$\mathrm{SpO}_{2}<95 \%$} \\
\hline$R R \geq$ age specific cut-off ${ }^{\star}$ & 6519 & 1460 & 0.60 & 0.46 & $1.11(1.07$ to 1.15$)$ & $0.87(0.83$ to 0.92$)$ \\
\hline $\begin{array}{l}R R \geq 5 \text { above age-specific } \\
\text { cut-offt }\end{array}$ & 5529 & 1242 & 0.51 & 0.54 & $1.11(1.06$ to 1.16$)$ & $0.90(0.87$ to 0.95$)$ \\
\hline $\begin{array}{l}R R \geq 10 \text { above age- } \\
\text { specific cut-off } \ddagger\end{array}$ & 4400 & 1016 & 0.42 & 0.64 & 1.15 (1.09 to 1.22$)$ & $0.91(0.88$ to 0.95$)$ \\
\hline \multicolumn{7}{|l|}{$\mathrm{SpO}_{2}<90 \%$} \\
\hline$R R \geq$ age-specific cut-off ${ }^{\star}$ & 2835 & 731 & 0.30 & 0.78 & 1.33 (1.24 to 1.43$)$ & $0.90(0.88$ to 0.93$)$ \\
\hline $\begin{array}{l}R R \geq 5 \text { above age-specific } \\
\text { cut-offt }\end{array}$ & 2465 & 641 & 0.26 & 0.81 & 1.35 (1.25 to 1.46$)$ & $0.92(0.89$ to 0.94$)$ \\
\hline $\begin{array}{l}R R \geq 10 \text { above age- } \\
\text { specific cut-off } \neq\end{array}$ & 2064 & 551 & 0.23 & 0.84 & $1.40(1.28$ to 1.53$)$ & $0.92(0.90$ to 0.94$)$ \\
\hline \multicolumn{7}{|l|}{$\mathrm{SpO}_{2}<85 \%$} \\
\hline$R R \geq$ age-specific cut-off* & 1204 & 342 & 0.14 & 0.91 & $1.52(1.36$ to 1.71$)$ & 0.95 (0.93 to 0.96$)$ \\
\hline $\begin{array}{l}R R \geq 5 \text { above age-specific } \\
\text { cut-off } \dagger\end{array}$ & 1049 & 305 & 0.12 & 0.92 & 1.57 (1.39 to 1.79$)$ & 0.95 (0.94 to 0.97$)$ \\
\hline $\begin{array}{l}R R \geq 10 \text { above age- } \\
\text { specific cut-off } \neq\end{array}$ & 887 & 263 & 0.11 & 0.93 & $1.62(1.41$ to 1.86$)$ & $0.96(0.94$ to 0.97$)$ \\
\hline
\end{tabular}

Bold values are statistically significant.

${ }^{*} \mathrm{RR}$ of $\geq 60$ per minute in infants $<2$ months old, $>50$ per minute in infants $2-11$ months old, or $\geq 40$ per minute in children 12-59 months old.

†RR of $\geq 65$ per minute in infants $<2$ months old, $>55$ per minute in infants $2-11$ months old, or $\geq 45$ per minute in children 12-59 months old.

$\ddagger R R$ of $\geq 70$ per minute in infants $<2$ months old, $>60$ per minute in infants $2-11$ months old, $>50$ per minute in children $12-59$ months old.

$\mathrm{SPO}_{2}$, oxygen saturation.

used to identify pneumonia in resource-limited settings, including tachypnoea and chest indrawing, had poor specificity for the diagnosis of radiographic pneumonia. The test characteristics of all signs and symptoms did not materially differ based on the presence or absence of wheeze. Our study demonstrates that no individual symptom or physical examination finding was strongly associated with radiographic pneumonia in children. Extreme levels of hypoxaemia were highly specific for radiographic pneumonia, although sensitivity was low. Lower thresholds of hypoxaemia commonly used in clinical settings (ie, $<95 \%$ and $<90 \%)^{19}$ demonstrated moderate sensitivity and specificity for the identification of radiographic pneumonia.

The WHO guideline recommends oral amoxicillin treatment in children 2-59 months of age with chest indrawing. ${ }^{12} 20$ In our analysis, chest indrawing alone was not specific for the radiographic diagnosis of pneumonia. It has been suggested that children with chest indrawing and signs of severe respiratory distress, oxygen desaturations, moderate malnutrition, and unknown HIV-status in HIV-endemic areas be monitored daily or referred for inpatient management given their risk for decompensation. $^{21}$ In a large prospective pneumonia aetiology study in low- and middle-income countries, tachypnoea, hypoxaemia, crackles, and fever were all independently associated with an abnormal chest radiograph. ${ }^{11}$ Oxygen desaturation was the most specific single sign for radiographic pneumonia in our study. In a small, retrospective study of 147 children in Rwanda, oxygen desaturation was significantly associated with radiographic pneumonia. ${ }^{22}$ In a larger prospective study of nearly 400 children in Norway, hypoxaemia (defined as $\mathrm{SpO}_{2}<92 \%$ ) independently predicted radiographic pneumonia and was the only clinical feature that predicted radiographic pneumonia. ${ }^{23}$ If available, $\mathrm{SpO}_{2}$ should be measured in children evaluated for pneumonia as the presence of extreme levels of hypoxaemia is highly specific for the diagnosis of radiographic pneumonia.

Although tachypnoea is used to assess for pneumonia in many resource-limited settings, our data showed that commonly used, age-specific RR thresholds were neither sensitive nor specific for the identification of radiographic pneumonia in children. This finding adds further support to the body of evidence suggesting that tachypnoea should not be used as an isolated finding 
Table 5 Test characteristics of varying respiratory rates (RRs) with fever (temperature $\geq 38^{\circ} \mathrm{C}$ ) in children

\section{Patients \\ with RR}

above Radiographic

threshold, pneumonia, Positive likelihood Negative likelihood

RR and fever

$n(n=9410) \quad n(n=2335)$

Sensitivity Specificity ratio $(95 \% \mathrm{Cl})$

ratio $(95 \% \mathrm{Cl})$

\begin{tabular}{|c|c|c|c|c|c|c|}
\hline \multicolumn{7}{|l|}{ Afebrile (temperature $<38^{\circ} \mathrm{C}$ ) } \\
\hline$R R \geq$ age-specific cut-off* & 5809 & 1073 & 0.46 & 0.51 & $0.94(0.89$ to 0.99$)$ & $1.06(1.01$ to 1.10$)$ \\
\hline $\begin{array}{l}R R \geq 5 \text { above age-specific } \\
\text { cut-off }\end{array}$ & 4619 & 856 & 0.37 & 0.61 & $0.94(0.89$ to 1.00$)$ & $1.04(1.00$ to 1.07$)$ \\
\hline $\begin{array}{l}R R \geq 10 \text { above age-specific } \\
\text { cut-off } \neq\end{array}$ & 3479 & 649 & 0.28 & 0.71 & 0.95 (0.88 to 1.02$)$ & 1.02 (0.99 to 1.05$)$ \\
\hline \multicolumn{7}{|l|}{ Febrile (temperature $\geq 38^{\circ} \mathrm{C}$ ) } \\
\hline $\mathrm{RR} \geq$ age-specific cut-off* & 3601 & 787 & 0.34 & 0.71 & $1.16(1.09$ to 1.24$)$ & $0.93(0.91$ to 0.96$)$ \\
\hline $\begin{array}{l}R R \geq 5 \text { above age-specific } \\
\text { cut-offt }\end{array}$ & 3045 & 678 & 0.29 & 0.76 & 1.19 (1.10 to 1.28$)$ & $0.94(0.91$ to 0.97$)$ \\
\hline $\begin{array}{l}R R \geq 10 \text { above age-specific } \\
\text { cut-off } \neq\end{array}$ & 2446 & 564 & 0.24 & 0.81 & 1.24 (1.14 to 1.35$)$ & $0.94(0.92$ to 0.97$)$ \\
\hline
\end{tabular}

Bold values are statistically significant.

${ }^{*} R R$ of $\geq 60$ per minute in infants $<2$ months old, $>50$ per minute in infants $2-11$ months old or $\geq 40$ per minute in children 12-59 months old.

†RR of $\geq 65$ per minute in infants $<2$ months old, $>55$ per minute in infants $2-11$ months old, or $\geq 45$ per minute in children 12-59 months old.

$\ddagger R R$ of $\geq 70$ per minute in infants $<2$ months old, $>60$ per minute in infants $2-11$ months old, $>50$ per minute in children $12-59$ months old.

to diagnose pneumonia and subsequently determine which children would benefit from antibiotic treatment. ${ }^{9} 102425$ Radiographic pneumonia, though often used as the reference standard for the diagnosis of pneumonia, should be interpreted in the context of its limitations including the potential delayed manifestations of radiographic findings, inability to reliably distinguish bacterial and viral infections, and variable inter-rater reliability among radiologists for certain findings suggestive of pneumonia. ${ }^{17}$ Our investigation used primary end point radiographic pneumonia, which was developed for vaccine trials to identify pneumonia that could be prevented by Streptococcus pneumoniae and Haemophilus influenzae $\mathrm{B}$ vaccines and it became a useful and a sensitive tool to evaluate vaccine outcomes. ${ }^{26} 27$ Primary end point radiographic pneumonia is a subset of all cases of clinical pneumonia. ${ }^{11}$ Our finding that tachypnoea is not strongly associated with radiographic pneumonia might partially explain the variable results from randomised trials comparing amoxicillin and placebo among children with fast breathing pneumonia. ${ }^{28-30}$ Furthermore, many children receiving a diagnosis of pneumonia in resource-limited settings may harbour other respiratory illnesses such as asthma or other viral infections as demonstrated by the Pneumonia Etiology Research for Child Health study group. ${ }^{31}$

Table 6 Test characteristics of varying oxygen saturations $\left(\mathrm{SpO}_{2}\right)$ without and with fever (temperature $\left.\geq 38^{\circ} \mathrm{C}\right)$ in children

\begin{tabular}{|c|c|c|c|c|c|c|}
\hline Fever and $\mathrm{SpO}_{2}$ & $\begin{array}{l}\text { Patients with } \\
\text { symptoms, n } \\
\text { (n=11 547) }\end{array}$ & $\begin{array}{l}\text { Radiographic } \\
\text { pneumonia, } n \\
(n=2323)\end{array}$ & Sensitivity & Specificity & $\begin{array}{l}\text { Positive likelihood } \\
\text { ratio }(95 \% \mathrm{Cl})\end{array}$ & $\begin{array}{l}\text { Negative likelihood } \\
\text { ratio }(95 \% \mathrm{Cl})\end{array}$ \\
\hline \multicolumn{7}{|c|}{ Afebrile (temperature $<38^{\circ} \mathrm{C}$ ) } \\
\hline $\mathrm{SpO}_{2}<95 \%$ & 4421 & 870 & 0.37 & 0.62 & $0.97(0.92$ to 1.03$)$ & 1.02 (0.98 to 1.05$)$ \\
\hline $\mathrm{SpO}_{2}<90 \%$ & 1827 & 407 & 0.18 & 0.85 & 1.14 (1.03 to 1.26$)$ & 0.97 (0.95 to 0.99$)$ \\
\hline $\mathrm{SpO}_{2}<85 \%$ & 810 & 192 & 0.08 & 0.93 & 1.23 (1.06 to 1.44$)$ & $0.98(0.97$ to 1.00$)$ \\
\hline \multicolumn{7}{|c|}{ Febrile (temperature $\geq 38^{\circ} \mathrm{C}$ ) } \\
\hline $\mathrm{SpO}_{2}<95 \%$ & 2636 & 666 & 0.29 & 0.79 & 1.34 (1.24 to 1.45$)$ & 0.91 (0.88 to 0.93$)$ \\
\hline $\mathrm{SpO}_{2}<90 \%$ & 1178 & 340 & 0.15 & 0.91 & 1.61 (1.43 to 1.81$)$ & 0.94 (0.92 to 0.96$)$ \\
\hline $\mathrm{SpO}_{2}<85 \%$ & 520 & 170 & 0.07 & 0.96 & $1.93(1.61$ to 2.30$)$ & 0.96 (0.95 to 0.97$)$ \\
\hline
\end{tabular}

Bold values are statistically significant. 
Treatment decisions for children with suspected pneumonia in low-income and middle-income countries rely largely on clinical findings, including tachypnoea and chest indrawing. ${ }^{12} 13$ This allows community health workers and healthcare providers at primary level health facilities to make decisions around antibiotic administration and the need for referral in areas with scarce resources. However, other signs, such as hypoxaemia, are critical to identify as it has been shown to be associated with radiographic pneumonia, ${ }^{9}{ }^{24}$ and carries up to a fivefold increased risk of mortality when compared with children without hypoxaemia in low- and middle-income countries. ${ }^{32-36}$ Our study identified extreme levels of hypoxaemia as highly specific for radiographic pneumonia. Though the WHO IMCI chart booklet recommends use of pulse oximetry when available, ${ }^{12}$ many low-resource settings lack this tool. ${ }^{37} 38$ However, the recent development of low-cost technologies for pulse oximetry, ${ }^{39}$ including hardware attached to mobile phones, ${ }^{40-42}$ may expand its use in resource-limited settings.

The major strength of our aggregated database containing individual patient-level data is our ability to evaluate the test characteristics of combinations of signs, symptoms, and physical examination findings for the radiographic diagnosis of pneumonia. Prior singlecentre studies have not been powered to identify which combinations of clinical findings could be used to identify radiographic pneumonia. ${ }^{24} 43-47$ Additionally, prior meta-analyses investigating the test characteristics of clinical signs and symptoms for the prediction of radiographic pneumonia observed that no single sign or symptom was highly accurate for the identification of radiographic pneumonia, ${ }^{910}$ and discussed the impetus for future studies to allow for the assessment of a combination of signs and symptoms to improve the care of children with suspected pneumonia. In this study, by aggregating patient-level data from ten investigations, we observed that by combining certain signs and symptoms, including tachypnoea, oxygen desaturation, and fever, we were able to improve the discriminator ability to identify radiographic pneumonia. The diagnostic performance of a combination of signs and symptoms should be explored in a prospective fashion to allow for a judicious approach to antibiotic treatment in children with suspected pneumonia.

\section{Limitations}

The results of this analysis should be interpreted in the context of their limitations. First, as many studies used in this analysis used the WHO IMCI definition of tachypnoea and lower chest indrawing as an inclusion criterion, there may be overestimation of the true sensitivity and specificity of tachypnoea in the radiographic diagnosis of childhood pneumonia. Also, the inclusion criterion of tachypnoea as defined by WHO thresholds limited our ability to assess the test characteristics of RRs below the WHO thresholds in the radiographic diagnosis of pneumonia. Second, there was no common standardised approach to define radiographic pneumonia across all 10 studies, though most studies included in this analysis used primary endpoint pneumonia or lobar consolidation, which is part of end point pneumonia definition. ${ }^{16}$ The inclusion of both primary end point pneumonia and lobar consolidation as the reference standard may have introduced some heterogeneity to our findings but improves the generalisability of our findings to more practical clinical settings. Third, lack of uniformity of recording some signs and symptoms across included studies may have led to overestimation or underestimation of the test characteristics for the signs and symptoms evaluated in this analysis. Fourth, we did not conduct formal statistical analyses to account for heterogeneity in the included studies' inclusion and exclusion criteria. Fifth, there was a high degree of heterogeneity with respect to study types, settings, type of clinician performing the evaluation, and patient population. Lastly, our findings may not be as applicable to extremely resource-limited settings in which chest radiography is not routinely available.

\section{CONCLUSIONS}

In this study, including $>15000$ children 0-59 months of age, we observed that no individual symptom or physical examination finding was predictive of end point radiographic pneumonia. The presence of tachypnoea as an isolated finding was neither sensitive nor specific, while extreme levels of hypoxaemia was a specific finding among children with radiographic pneumonia. Combinations of commonly used vital signs including temperature, $\mathrm{RR}$ and $\mathrm{SpO}_{2}$ improved the specificity for the identification of radiographic pneumonia.

\section{Author affiliations}

${ }^{1}$ Division of Emergency Medicine, Boston Children's Hospital, Harvard Medical School, Boston, Massachusetts, USA

${ }^{2}$ Center for Intervention Science in Maternal and Child Health, University of Bergen, Bergen, Norway

${ }^{3}$ Department of Epidemiology, "R. Gutiérrez" Children's Hospital, Buenos Aires, Argentina

${ }^{4}$ Pfizer Vaccines, Collegeville, Pennsylvania, USA

${ }^{5}$ Department of Child Health, Faculty of Medicine, Universitas Padjadjaran, Bandung, Indonesia

${ }^{6}$ Research Institute for Tropical Medicine, Manila, Philippines

${ }^{7}$ PNUD/National University, Montevideo, Uruguay

${ }^{8}$ Institute of Health \& Biomedical Innovation @ Centre for Children's Health Research, Queensland University of Technology, South Brisbane, Queensland, Australia

${ }^{9}$ Dirección de Control de Enfermedades Inmunoprevenibles, Ministerio de Salud de la Nación, Buenos Aires, Argentina

${ }^{10}$ Shoklo Malaria Research Unit, Mae Sot, Thailand

${ }^{11}$ Centre for Global Health, Usher Institute, The University of Edinburgh, Edinburgh, Scotland

${ }^{12}$ Institute for Global Health and Development, Queen Margaret University,

Edinburgh, Scotland

${ }^{13}$ Research Department, Innlandet Hospital Trust, Lillehammer, Norway

${ }^{14}$ Department of Maternal, Newborn, Child and Adolescent Health and Ageing, World Health Organization, Geneva, Switzerland

${ }^{15}$ Department of Maternal, Newborn, Child and Adolescent Health (Retired), World Health Organization, Geneva, Switzerland

${ }^{16}$ Pneumonia Research Partnership to Assess WHO Recommendations

Twitter Luis Martinez @Imartinezarroyo 
Acknowledgements We acknowledge the World Health Organization PREPARE study group members including Rajiv Bahl, Wilson M. Were, Lulu M. Muhe, Valerie D’Acremont, Donald M. Thea, Abdullah Brooks, Romina Libster, Joseph Mathew, Tabish Hazir, and Sunil Sazawal.

Contributors CAR, MIN, YBN, and SQ conceptualised the study and designed the analysis. MIN, SB, AG, BDG, CBK, ML, LM, K-AF0, ROR, CT, HC, HN, JF, LJW, and $\mathrm{MH}$ curated the data. YBN, LJW, and MH conducted the data analysis. All authors contributed to the interpretation of the data. CAR and MIN drafted the original draft of the manuscript. All authors critically reviewed and revised the manuscript.

Funding The study was funded by the Bill \& Melinda Gates Foundation (\#OPP1106190) through a grant to the WHO.

Disclaimer The funders had no role in the study design or in the collection, analysis, or interpretation of the data. The funders did not write the report and had no role in the decision to submit the paper for publication.

Competing interests None declared.

Patient and public involvement Patients and/or the public were not involved in the design, or conduct, or reporting, or dissemination plans of this research.

Patient consent for publication Not required.

Ethics approval As this study used de-identified data from existing studies, ethical approval was obtained from each site. Included studies which were sponsored by the WHO additionally received ethical approval from the WHO ethics review committee.

Provenance and peer review Not commissioned; externally peer reviewed.

Data availability statement Data may be made available on reasonable request.

Open access This is an open access article distributed in accordance with the Creative Commons Attribution Non Commercial (CC BY-NC 4.0) license, which permits others to distribute, remix, adapt, build upon this work non-commercially, and license their derivative works on different terms, provided the original work is properly cited, appropriate credit is given, any changes made indicated, and the use is non-commercial. See: http://creativecommons.org/licenses/by-nc/4.0/.

ORCID iD

Chris A Rees http://orcid.org/0000-0001-6449-0377

\section{REFERENCES}

1 Liu L, Oza S, Hogan D, et al. Global, regional, and national causes of child mortality in 2000-13, with projections to inform post-2015 priorities: an updated systematic analysis. Lancet 2015;385:430-40.

2 GBD 2017 Lower Respiratory Infections Collaborators. Quantifying risks and interventions that have affected the burden of lower respiratory infections among children younger than 5 years: an analysis for the global burden of disease study 2017. Lancet Infect Dis 2020;20:60-79.

3 UNICEF. Pneumonia and Diarrhoea: Tackling the Deadliest Diseases for the World's Poorest Children. New York: UNICEF, 2012.

4 Lynch T, Bialy L, Kellner JD, et al. A systematic review on the diagnosis of pediatric bacterial pneumonia: when gold is bronze. PLoS One 2010;5:e11989.

5 Bradley JS, Byington CL, Shah SS, et al. The management of community-acquired pneumonia in infants and children older than 3 months of age: clinical practice guidelines by the pediatric infectious diseases Society and the infectious diseases Society of America. Clin Infect Dis 2011:53:e25-76.

6 Cherian T, Mulholland EK, Carlin JB, et al. Standardized interpretation of paediatric chest radiographs for the diagnosis of pneumonia in epidemiological studies. Bull World Health Organ 2005;83:353-9.

7 Ben Shimol S, Dagan R, Givon-Lavi N, et al. Evaluation of the world Health organization criteria for chest radiographs for pneumonia diagnosis in children. Eur J Pediatr 2012;171:369-74.

8 Kelly MS, Crotty EJ, Rattan MS, et al. Chest radiographic findings and outcomes of pneumonia among children in Botswana. Pediatr Infect Dis J 2016;35:257-62.

9 Shah SN, Bachur RG, Simel DL, et al. Does this child have pneumonia?: the rational clinical examination systematic review. JAMA 2017;318:462-71.

10 Rambaud-Althaus C, Althaus F, Genton B, et al. Clinical features for diagnosis of pneumonia in children younger than 5 years: a systematic review and meta-analysis. Lancet Infect Dis 2015;15:439-50.
11 Fancourt N, Deloria Knoll M, Baggett HC, et al. Chest radiograph findings in childhood pneumonia cases from the multisite $\mathrm{PERCH}$ study. Clin Infect Dis 2017;64:S262-70.

12 World Health Organization. Integrated management of childhood illness (IMCI): chart booklet, 2014. Available: https://apps.who.int/ iris/bitstream/handle/10665/104772/9789241506823_Chartbook eng.pdf;jsessionid=BE494386E475C23748C604BA2CD963B4? sequence=16 [Accessed 6 Nov 2019].

13 World Health Organization. Recommendations for management of common childhood conditions: evidence for technical update of pocket book recommendations. Geneva: WHO, 2012.

14 World Health Organization. Programme for the control of acute respiratory infections. technical bases for the who recommendations on the management of pneumonia in children at first-level health facilities, 1991. Available: https://apps.who.int/iris/ bitstream/handle/10665/61199/WHO_ARI_91.20.pdf;jsessionid= 8AB3354797C019D582E86BBD09C84A69? sequence $=1$ [Accessed 6 Nov 2019]

15 Nair H, Simões EA, Rudan I, et al. Global and regional burden of hospital admissions for severe acute lower respiratory infections in young children in 2010: a systematic analysis. Lancet 2013;381:1380-90.

16 Fancourt N, Deloria Knoll M, Barger-Kamate B, et al. Standardized interpretation of chest radiographs in cases of pediatric pneumonia from the PERCH study. Clin Infect Dis 2017;64:S253-61.

17 Neuman MI, Lee EY, Bixby S, et al. Variability in the interpretation of chest radiographs for the diagnosis of pneumonia in children. $J$ Hosp Med 2012;7:294-8.

18 WHO. Integrated management of childhood illness: conclusions. who division of child health and development. Bull World Health Organ 1997;75 Suppl 1:119-28.

19 World Health Organization. Oxygen therapy for children: a manual for health workers, 2016. Available: https://apps.who.int/iris/bitstream/ handle/10665/204584/9789241549554_eng.pdf;jsessionid=7E66 65B4A7D61A95AC8C23FB6E205DD8? sequence=1 [Accessed 15 Oct 2019].

20 World Health Organization. Revised who classification and treatment of childhood pneumonia at health facilities, 2014. Available: https:// apps.who.int/iris/bitstream/handle/10665/137319/9789241507813 eng.pdf?sequence=1 [Accessed 15 Nov 2019]

21 McCollum ED, Ginsburg AS. Outpatient management of children with World Health organization chest Indrawing pneumonia: implementation risks and proposed solutions. Clin Infect Dis 2017;65:1560-4.

22 Modi P, Munyaneza RBM, Goldberg E, et al. Oxygen saturation can predict pediatric pneumonia in a resource-limited setting. J Emerg Med 2013;45:752-60.

23 Berg AS, Inchley CS, Fjaerli HO, et al. Clinical features and inflammatory markers in pediatric pneumonia: a prospective study. Eur J Pediatr 2017;176:629-38.

24 Neuman MI, Monuteaux MC, Scully KJ, et al. Prediction of pneumonia in a pediatric emergency department. Pediatrics 2011;128:246-53.

25 Shah S, Bachur R, Kim D, et al. Lack of predictive value of tachypnea in the diagnosis of pneumonia in children. Pediatr Infect Dis J 2010;29:406-9.

26 Mahomed N, Fancourt N, de Campo J, et al. Preliminary report from the world health organisation chest radiography in epidemiological studies project. Pediatr Radiol 2017;47:1399-404.

27 World Health Organization Pneumonia Vaccine Trial Investigators Group. Standardization of interpretation of chest radiographs for the diagnosis of pneumonia in children, 2001. Available: https://apps. who.int/iris/bitstream/handle/10665/66956/WHO_V_and_B_01.35. pdf? sequence=1 [Accessed 15 Nov 2019].

28 Ginsburg AS, Mvalo T, Nkwopara E, et al. Placebo vs amoxicillin for nonsevere Fast-Breathing pneumonia in Malawian children aged 2 to 59 months: a double-blind, randomized clinical Noninferiority trial. JAMA Pediatr 2019;173:21-8.

29 Hazir T, Nisar YB, Abbasi S, et al. Comparison of oral amoxicillin with placebo for the treatment of World health organization-defined nonsevere pneumonia in children aged 2-59 months: a multicenter, double-blind, randomized, placebo-controlled trial in Pakistan. Clin Infect Dis 2011:52:293-300.

30 Tikmani SS, Muhammad AA, Shafiq Y, et al. Ambulatory treatment of fast breathing in young infants aged. Clin Infect Dis 2017;64:184-9.

31 Pneumonia Etiology Research for Child Health (PERCH) Study Group. Causes of severe pneumonia requiring hospital admission in children without HIV infection from Africa and Asia: the PERCH multi-country case-control study. Lancet 2019;394:757-79.

32 Hooli S, Colbourn T, Lufesi N, et al. Predicting hospitalised paediatric pneumonia mortality risk: an external validation of RISC and mRISC, 
and local tool development (RISC-Malawi) from Malawi. PLoS One 2016;11:e0168126.

33 Junge S, Palmer A, Greenwood BM, et al. The spectrum of hypoxaemia in children admitted to hospital in the Gambia, West Africa. Trop Med Int Health 2006;11:367-72.

34 Usen S, Weber M, Mulholland K, et al. Clinical predictors of hypoxaemia in Gambian children with acute lower respiratory tract infection: prospective cohort study. BMJ 1999;318:86-91.

35 Onyango FE, Steinhoff MC, Wafula EM, et al. Hypoxaemia in young Kenyan children with acute lower respiratory infection. BMJ 1993;306:612-5.

36 Lazzerini M, Sonego M, Pellegrin MC. Hypoxaemia as a mortality risk factor in acute lower respiratory infections in children in low and middle-income countries: systematic review and meta-analysis. PLoS One 2015;10:e0136166.

37 McCollum ED, Bjornstad E, Preidis GA, et al. Multicenter study of hypoxemia prevalence and quality of oxygen treatment for hospitalized Malawian children. Trans $R$ Soc Trop Med Hyg 2013;107:285-92.

38 Graham H, Tosif S, Gray A, et al. Providing oxygen to children in hospitals: a realist review. Bull World Health Organ 2017;95:288-302.

39 Shokouhian M, Morling RCS, Kale I. Low cost MATLABbased pulse oximeter for deployment in research and development applications. Conf Proc IEEE Eng Med Biol Soc 2013;2013:1740-3.

40 Tomlinson S, Behrmann S, Cranford J, et al. Accuracy of smartphone-based pulse oximetry compared with HospitalGrade pulse oximetry in healthy children. Telemed J E Health 2018;24:527-35.

41 Petersen CL, Gan H, Maclnnis MJ, et al. Ultra-low-cost clinical pulse oximetry. Conf Proc IEEE Eng Med Biol Soc 2013;2013:2874-7.

42 Jordan TB, Meyers CL, Schrading WA, et al. The utility of iPhone oximetry apps: a comparison with standard pulse oximetry measurement in the emergency department. Am J Emerg Med 2020;38:925-8.

43 Leventhal JM. Clinical predictors of pneumonia as a guide to ordering chest roentgenograms. Clin Pediatr 1982;21:730-4.

44 Lynch T, Platt R, Gouin S, et al. Can we predict which children with clinically suspected pneumonia will have the presence of focal infiltrates on chest radiographs? Pediatrics 2004;113:e186-9.

45 Mahabee-Gittens EM, Bachman DT, Shapiro ED, et al. Chest radiographs in the pediatric emergency department for children. Clin Pediatr 1999;38:395-9.
46 Mahabee-Gittens EM, Dowd MD, Beck JA, et al. Clinical factors associated with focal infiltrates in wheezing infants and toddlers. Clin Pediatr 2000;39:387-93.

47 Mahabee-Gittens EM, Grupp-Phelan J, Brody AS, et al. Identifying children with pneumonia in the emergency department. Clin Pediatr 2005;44:427-35.

48 Puumalainen T, Quiambao B, Abucejo-Ladesma E, et al. Clinical case review: a method to improve identification of true clinical and radiographic pneumonia in children meeting the world Health organization definition for pneumonia. BMC Infect Dis 2008;8:95.

49 Arcay JD, Ocampo AF, Solis RK, et al. Radiology quality assurance in a developing country setting: the 11-valent pneumococcal conjugate vaccine trial, Bohol, Philippines. Vaccine 2007;25:2528-32.

50 Basnet S, Shrestha PS, Sharma A, et al. A randomized controlled trial of zinc as adjuvant therapy for severe pneumonia in young children. Pediatrics 2012;129:701-8.

51 Gentile Ángela, Juarez MdelV, Luciön MF, et al. Influence of respiratory viruses on the evaluation of the 13-valent pneumococcal conjugate vaccine effectiveness in children under 5 years old: a time-series study for the 2001-2013 period. Arch Argent Pediatr 2015;113:310-6.

52 Gessner BD, Sutanto A, Linehan M, et al. Incidences of vaccinepreventable Haemophilus influenzae type B pneumonia and meningitis in Indonesian children: hamlet-randomised vaccine-probe trial. Lancet 2005;365:43-52.

53 Hortal M, Estevan M, Iraola I, et al. A population-based assessment of the disease burden of consolidated pneumonia in hospitalized children under five years of age. Int $J$ Infect Dis 2007;11:273-7.

54 Tan KK, Dang DA, Kim KH, et al. Burden of hospitalized childhood community-acquired pneumonia: a retrospective cross-sectional study in Vietnam, Malaysia, Indonesia and the Republic of Korea. Hum Vaccin Immunother 2018;14:95-105.

55 O'Grady K-AF, Torzillo PJ, Ruben AR, et al. Identification of radiological alveolar pneumonia in children with high rates of hospitalized respiratory infections: comparison of WHO-defined and pediatric pulmonologist diagnosis in the clinical context. Pediatr Pulmonol 2012;47:386-92

56 Ferrero F, Nascimento-Carvalho CM, Cardoso M-R, et al. Radiographic findings among children hospitalized with severe community-acquired pneumonia. Pediatr Pulmonol 2010;45:1009-13.

57 Turner C, Turner P, Carrara V, et al. High rates of pneumonia in children under two years of age in a South East Asian refugee population. PLoS One 2013;8:e54026. 